\title{
Capripoxviruses: Exploring the genetic relatedness between field and vaccine strains from Egypt
}

\author{
Sherin Reda Rouby ${ }^{1}$, Abdel-Hamid Bazid² ${ }^{2}$ Momtaz Wasfy ${ }^{3}$ and Magdy El-Sayed ${ }^{3,4}$
}

1. Department of Veterinary Medicine, Faculty of Veterinary Medicine, Beni-Suef University, Beni-Suef 62511, Egypt; 2. Department of Virology, Faculty of Veterinary Medicine, University of Sadat City, Sadat City, Menoufia 32897, Egypt;

3. Department of Research and Development, Middle East for Veterinary vaccine Company (ME-VAC), Second Industrial Area, El-Salhya El-Gedida, Sharqia, Egypt; 4. Department of Internal Medicine and Infectious Diseases, Faculty of Veterinary Medicine, Cairo University, Giza Governorate 12613, Egypt.

Corresponding author: Sherin Reda Rouby, e-mail: shereen.rouby@vet.bsu.edu.eg Co-authors: AB: abdelhameed.mousa@vet.usc.edu.eg, MW: bazid1976@yahoo.com, ME: magdyelsayed@ubmegypt.com

Received: 10-08-2019, Accepted: 29-10-2019, Published online: 11-12-2019

doi: www.doi.org/10.14202/vetworld.2019.1924-1930 How to cite this article: Rouby SR, Bazid A, Wasfy M, El-Sayed M (2019) Capripoxviruses: Exploring the genetic relatedness between field and vaccine strains from Egypt, Veterinary World, 12(12): 1924-1930.

\begin{abstract}
Background and Aim: Lumpy skin disease (LSD) and sheep pox are economically important Capripoxvirus-induced diseases of cattle and sheep, respectively. Despite the extensive vaccination program adopted by Egyptian veterinary authorities, LSD and sheep pox are still prevalent and spread throughout the whole country. The current study was designed for molecular characterization and phylogenetic analysis of LSD virus (LSDV) and Sheep pox virus (SPPV) recovered from field cases in Egypt along with vaccinal strains to assess their genetic relatedness.

Materials and Methods: Skin biopsies were collected from naturally infected cases of LSD in Ismailia ( $\mathrm{n}=3$ farms) and Beni-Suef ( $\mathrm{n}=2$ farms) Governorates and sheep pox in Beni-Suef ( $\mathrm{n}=1$ flock). Virus isolation was carried out on primary ovine fetal kidney and heart cell cultures. DNA was extracted from infected materials (skin lesions, infected cell cultures) as well as LSDV Neethling vaccine strain and Romanian SPPV vaccine strain. Polymerase chain reaction was performed using oligonucleotide primers targeting the entire open reading frame of G protein-coupled receptors (GPCR) gene and gene sequences were analyzed.

Results: Virus isolation on primary ovine fetal kidney and heart cell culture revealed a cytopathic effect at the third passage characterized by rounding of infected cells and margination of nuclear chromatin. Comparative sequence analysis of GPCR gene revealed that Egyptian LSDV isolated from Ismailia and Beni-Suef shared 99:100\% nucleotide and amino acid (AA) identities with each other. In comparison to the vaccinal strains, Egyptian LSDV isolates shared 98:99 nucleotide and AA identities with LSDV Neethling vaccine strain and 93:94\% with SPPV Romanian vaccine strain. No differences at the nucleotide or AAs were observed between the SPPV vaccine and virulent strains (100\% identity). Phylogenetic analyses revealed that LSDV Neethling vaccine strain is more related to field Egyptian LSDV and clustered within the LSDV group while Romanian SPPV vaccine strain clustered in a separate clade with SPPV field isolates.
\end{abstract}

Conclusion: Comparative sequencing and phylogenetic analyses of the GPCR gene reveal a minimal genetic variation between LSDV field isolates from different locations and a close relationship between virulent field strains and homologous vaccines.

Keywords: Capripoxvirus, G protein-coupled receptors gene, phylogenetic, Romanian.

\section{Introduction}

Lumpy skin disease (LSD) and sheep pox are economically important Capripoxvirus (CaPV)induced diseases of cattle and sheep, respectively. LSD virus (LSDV) and Sheep pox virus (SPPV) are categorized within the genus $\mathrm{CaPV}$ in the family Poxviridae [1].

LSD is an acute to subacute disease of cattle characterized by fever, rapid eruption of numerous

Copyright: Rouby, et al. Open Access. This article is distributed under the terms of the Creative Commons Attribution 4.0 International License (http://creativecommons.org/licenses/by/4.0/), which permits unrestricted use, distribution, and reproduction in any medium, provided you give appropriate credit to the original author(s) and the source, provide a link to the Creative Commons license, and indicate if changes were made. The Creative Commons Public Domain Dedication waiver (http://creativecommons.org/ publicdomain/zero/1.0/) applies to the data made available in this article, unless otherwise stated. circumscribed skin nodules, and generalized lymphadenitis [2-5]. The cost-effective of the disease was contributed to its high morbidity rate rather than mortality [5]. Geographically, the African continent was the first to record LSD incursions; however, the disease continues its spread to the Middle East and recently to Europe $[1,5,6]$. Regarding Egypt, the disease was first reported in May 1988 among cattle in Ismailia [7]. In early 2006, LSD reemerged in Egypt in a massive outbreak producing severe financial losses to livestock in different localities of Egypt [8].

Sheep pox is a highly contagious disease of small ruminants [9] characterized by fever, generalized pock lesions with high morbidity and mortality $[4,10]$. The disease regularly occurs in Asia and North Africa; later, several outbreaks were recorded in Greece [11] and Bulgaria [1]. 
There is no doubt that vaccination is the most effective way to control CaPV diseases [1]. Due to the cross-protection within the genus $\mathrm{CaPV}$, any $\mathrm{CaPV}$ isolate could be used as a vaccine against LSDV [12]. In the endemic area with sheep pox, the live attenuated sheep pox vaccine was used for controlling both LSD and sheep pox.

In Egypt, the Kenyan SGP O-240 vaccine was used during LSD incursion in 2005-2006 [13]. At present, Romanian SPPV vaccine strain is used by Egyptian veterinary authorities to immunize both small ruminants and cattle against CaPVs; however, the reoccurrence of an outbreak in vaccinated animals has been reported [14]. Under this situation, molecular characterization of field virulent and vaccinal strains is necessary to determine their genetic relatedness.

In the current study, G protein-coupled receptors (GPCR) gene was used for molecular characterization and phylogenetic analysis of LSDV and SPPV circulating in the field along with vaccinal strains to assess their genetic relatedness.

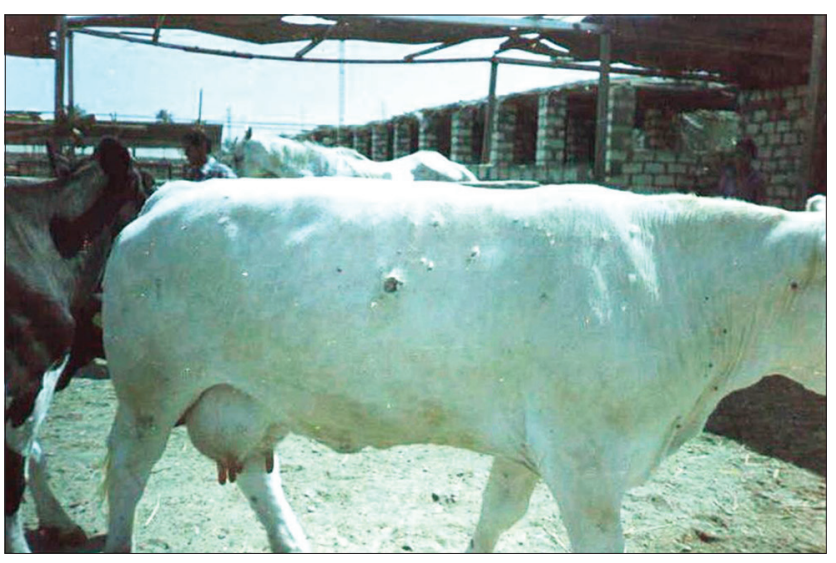

Figure-1: Skin lesions in a cow naturally infected with lumpy skin disease virus.

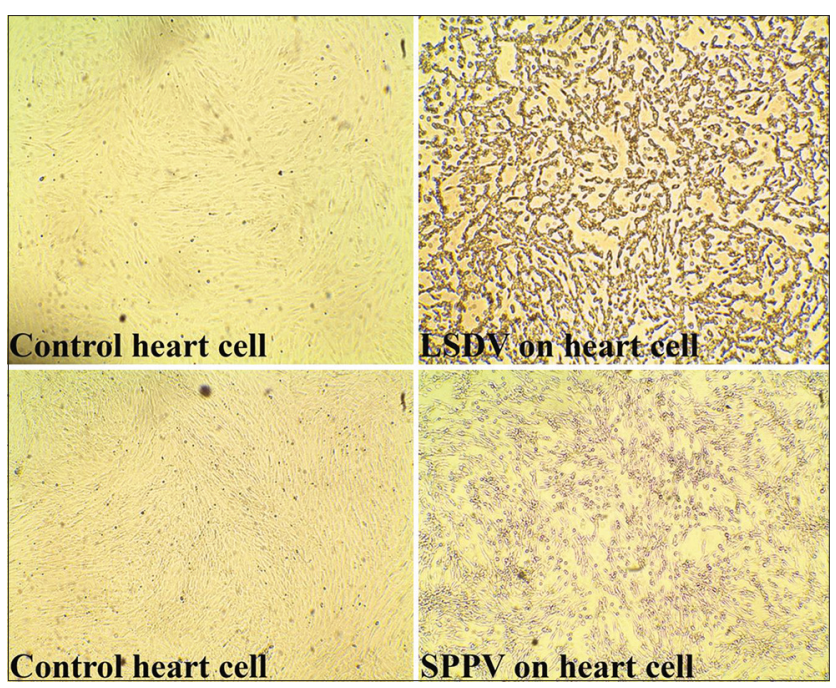

Figure-2: Lumpy skin disease virus and Sheep pox virus cytopathic at the third passage on cell culture.

\section{Materials and Methods}

\section{Ethical approval}

All animal handling procedures, as well as samples collection and disposal, were approved by the animal care and use committee of the Faculty of Veterinary Medicine, University of Sadat City, Egypt, according to the guidelines and recommendations of the European Communities Council Directive 1986 (86/609/EEC).

\section{Animals and clinical samples}

From June 2015 to September 2016, LSD and sheep pox were suspected among dairy cattle herds located in private farms belonging to Ismailia $(n=3)$ and Beni-Suef $(\mathrm{n}=2)$ Governorates and one sheep flock in Beni-Suef Governorate, respectively. All farms were clinically examined and a total of five nodular skin lesions were collected from diseased cattle with skin eruption all over the body while skin lesions were collected and pooled from infected sheep pox flock showing generalized pock lesions. The collected samples were kept at $-20^{\circ} \mathrm{C}$ for virus isolation and polymerase chain reaction (PCR).

\section{Virus strains}

South African Neethling vaccine strain (Lumpyvax ${ }^{\circledR}$, MSD) each $1 \mathrm{~mL}(1$ dose) of the vaccine contains $10^{4}$ TCID50 of freeze-dried, live, attenuated virus (SIS Neethling-type)from the Republic of South Africa and Romanian SPPV vaccine strain provided from the Pox Department, Veterinary Serum and Vaccine Research Institute, Abbassia, Cairo, Egypt, was used in the molecular study $\left(10^{3} \mathrm{TCID} 50 / \mathrm{ml}\right)$.

\section{Virus isolation}

Skin biopsies were used for the isolation of LSDV and SPPV according to Tuppurainen et al. [15]. Briefly, the skin tissue samples were minced and homogenized in a sterile condition by

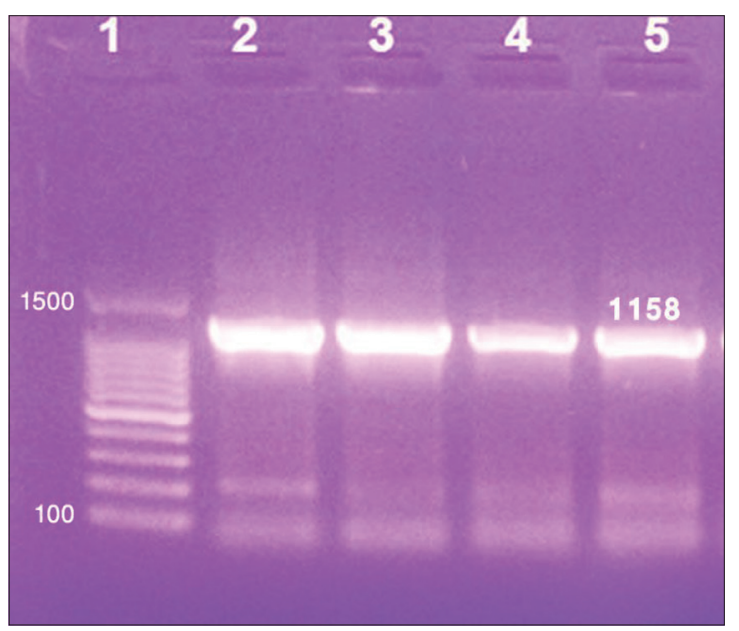

Figure-3: Gel electrophoresis of $G$ protein-coupled chemokine receptor gene-based polymerase chain reaction. Lane 1: 100 bp DNA ladder, Lane 2: Lumpy skin disease virus (LSDV) (Neethling vaccine strain), Lane 3: Sheep pox virus (SPPV) (Romanian vaccine), Lane 4: LSDV (field strain), Lane 5: SPPV (field strain). 


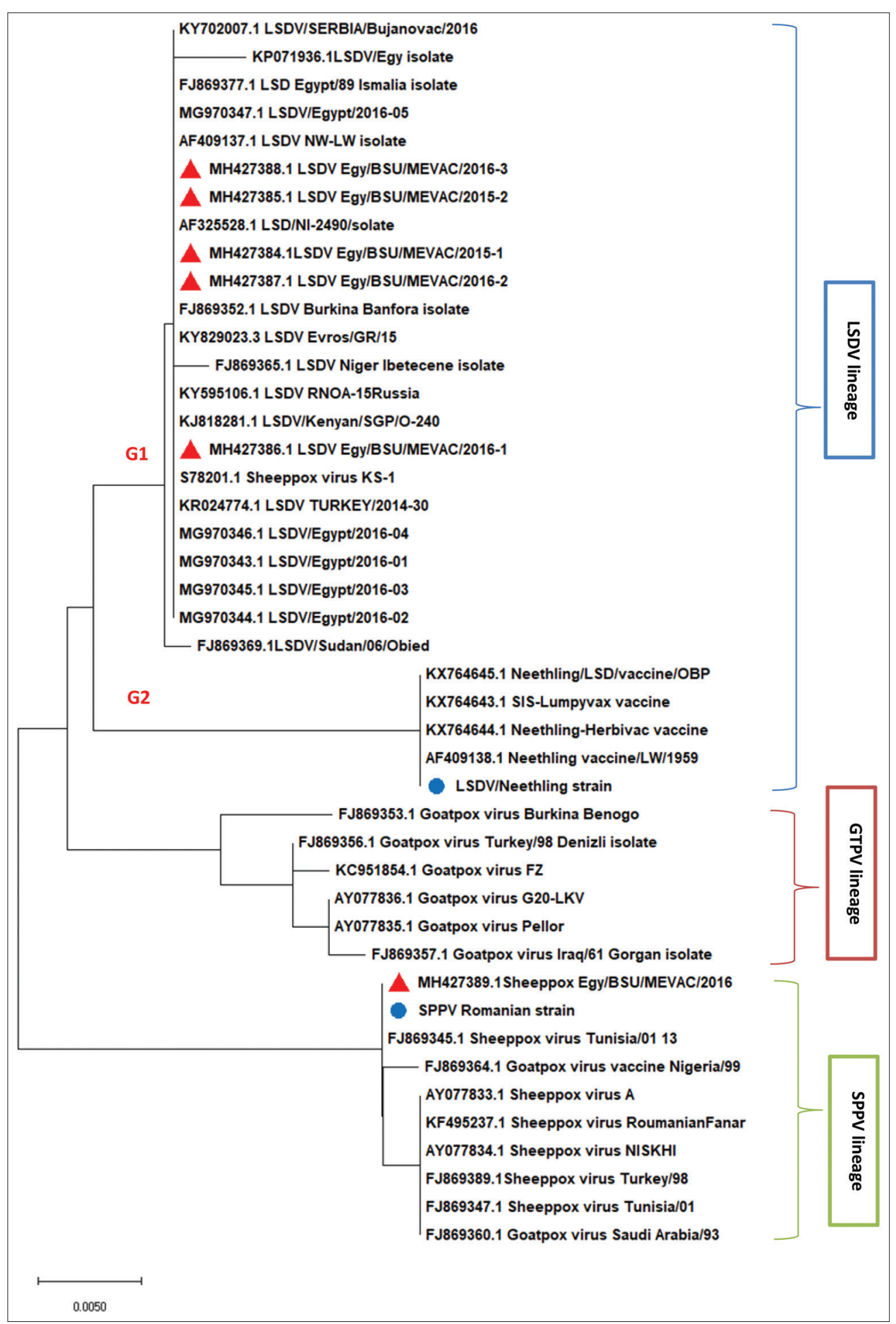

Figure-4: Phylogenetic analysis of the G protein-coupled chemokine receptor gene. The tree was generated using MEGA $X$ program by the neighbor-joining analysis. Bootstrap confidence values were calculated on 1000 replicates according to the maximum likelihood approach. Sequences obtained in this study are labeled ( $\mathbf{A}$ for lumpy skin disease virus and Sheep pox virus field isolates and 0 for vaccinal strains.

electric homogenizer (IKA, Model: T25D; Germany). A suspension of $10 \mathrm{~mL}$ of phosphate-buffered saline with antibiotics $(0.1 \mathrm{mg}$ gentamycin, $0.05 \mathrm{mg}$ ampicillin, and $5 \mu \mathrm{g}$ amphotericin $\mathrm{B}$ for each $\mathrm{mL}$ ) was added, then left to stand overnight at $4^{\circ} \mathrm{C}$. The suspension was centrifuged for $5 \mathrm{~min}$ at $2000 \mathrm{rpm}$ to eliminate any gross particles, and then, $0.5 \mathrm{~mL}$ of supernatant was transferred into monolayer of primary ovine fetal kidney and heart cells growing in tissue culture flasks (T25) and maintained in Minimum Essential Medium, Hank's salts with L-glutamine, $0.2 \%$ sodium bicarbonate, $10 \%$ fetal calf serum, $100 \mathrm{U} / \mathrm{ml}$ penicillin, and $100 \mu \mathrm{g} / \mathrm{ml}$ streptomycin. Cultures were observed daily for the cytopathic effect (CPE) for 14 days. Further, a passage for another 14 days was mandatory in case of negative culture into fresh monolayers. 
Table-1: Deduced ammino acid sequence of G protein-coupled checmokine receptor gene.

AF325528.1_LSD/NI-2490/isolate KJ818281.1_LSDV/Kenyan/SGP/O-240 KY702007.1_LSDV/SERBIA/BujanovaC FJ869369.1 ISDV/Sudan/06/Obied KP071936.1LSDV/EgY_isolate MH427384.1LSDV_EgY/BSU/MEVAC/2015/1 MH427385.1_LSDV_EgY/BSU/MEVAC/2015/2 MH427386.1 LSDVEGY/BSU/MEVAC/2016/1 MH427387.1_LSDV_EgY/BSU/MEVAC/2016/2 MH427388.1_LSDV_EgY/BSU/MEVAC/2016/3 KX764645.1_Neethling/LSD/vaccine kX764643.1_SIS-Iumpyvax_vaccine AF409138.1_Neethling_vaccine/Lw/ LSDV/Neethling_strain S78201.1_Sheeppox_virus_KS-1 AY077833.1_Sheeppox_virus_A MH427389.1Sheeppox_EgY/BSU/MEVAC016 SPPV_Romanian_strain

KF 495237.1_Sheeppox_virus_Rouman AY077834.1_Sheeppox_virus_NISKHI KC951854.1_Goatpox_virus_F KC951854.1_Goatpox_virus_FZ
AY077835.1_Goatpox_virus_Pellox

AF325528.1_LSD/NI-2490/isolate KJ818281.1_ISDV/Kenyan/SGP/O-240 KY702007.1_LSDV/SERBIA/Bujanovac FJ869369.1LSDV/Sudan/06/Obied KP071936.1LSDV/EgY_isolate MH427384.1LSDV_EgY/BSU/MEVAC/2015/1 MH427385.1 LSDV EgY/BSU/MEVAC/2015/2 MH427386.1_LSDVEGY/BSU/MEVAC/2016/1 MH427387.1_LSDV_EgY/BSU/MEVAC/2016/2 MH427388.1_LSDV_EgY/BSU/MEVAC/2016/3 KX764645.1_Neethling/LSD/vaccine KX764643.1_SIS-Iumpyvax_vaccine AF409138.1_Neethling_vaccine/LW/ LSDV/Neethling_strain

S78201.1_Sheeppox_virus_ks-1 AY077833.1_Sheeppox_virus_A MH427389.1Sheeppox_EgY/BSU/MEVAC016 MH427389.1Sheeppox_Egy/ SPPV_Romanian_strain
KF 495237.1_Sheeppox_virus_Rouman AY077834.1_Sheeppox_virus_NISKH KC951854.1_Goatpox_virus_FZ AY077835.1_Goatpox_virus_Pellor

AF325528.1_ISD/NI-2490/isolate KJ818281.1_LSDV/Kenyan/SGP/O-240 KY702007.1_LSDV/SERBIA/Bujanovac FJ869369.1 LSDV/Sudan/06/Obied KP071936.1LSDV/EgY_isolate MH427384.1LSDV_EgY/BSU/MEVAC/2015/1 MH427385.1_LSDV_EgY/BSU/MEVAC/2015/2 MH427386.1_LSDV_EgY/BSU/MEVAC/2016/1 MH427387.1_LSDV_EgY/BSU/MEVAC/2016/2 MH427388.1_LSDVEGY/BSU/MEVAC/2016/3 KX764645.1 Neethling/LSD/vaccine KX764643.1_SIS-Iumpyvax_vaccine KX764643.1_SIS-Iumpyvax_vaccine
AF409138.1_Neethling_vaccine/LW/ AF409138.1_Neethling_V

S78201.1_Sheeppox_virus_ks-1 AY077833.1_Sheeppox_virus_A MH427389.1Sheeppox_EgY/BSU/MEVAC016 SPPV_Romanian_strain

KF 495237.1_Sheeppox_virus_Rouman AY077834.1_Sheeppox_virus_NISKHI AY077834.1_Sheeppox_virus_NZ KC951854.1_Goatpox_virus_FZ
AY077835.1_Goatpox_virus_Pellor

AF325528.1_ISD/NI-2490/isolate KJ818281.1_ISDV/Kenyan/SGP/O-240 KY702007.1_LSDV/SERBIA/Bujanova FJ869369.1LSDV/Sudan/06/Obied KP071936.1LSDV/EgY_isolate MH427384 .1LSDV_EgY/BSU/MEVAC/2015/1 MH427385.1 LSDV EgY/BSU/MEVAC/2015/2 MH427385.1_LSDV_EgY/BSU/MEVAC/2015/2 MH427386.1_LSDV_EgY/BSU/MEVAC/2016/1
MH427387.1_ISDV_EgY/BSU/MEVAC/2016/2 MH427387.1_LSDV_EgY/BSU/MEVAC/2016/2
MH427388.1_LSDVEgY/BSU/MEVAC/2016/3 KX764645.1_Neethling/LSD/vaccine KX764643.1 SIS-Lumpyvax vaccine AF409138.1_Neethling_vaccine/LW/ LSDV/Neethling_strain

S78201.1_Sheeppox_virus_KS-1 578201.1_Sheeppox_virus_KS-1
AY077833.1_Sheeppox_virus_A AY077833.1_Sheeppox_virus_A
MH427389.1Sheeppox_Egy/BSU/MEVAC01 MH427389.1Sheeppox_Eg
SPPV Romanian strain SPPV_Romanian_strain
KF495237.1_Sheeppox_virus_Rouman AY077834.1_Sheeppox_virus_NISKHI KC951854.1_Goatpox_virus_FZ AY077835.1_Goatpox_virus_Pellor

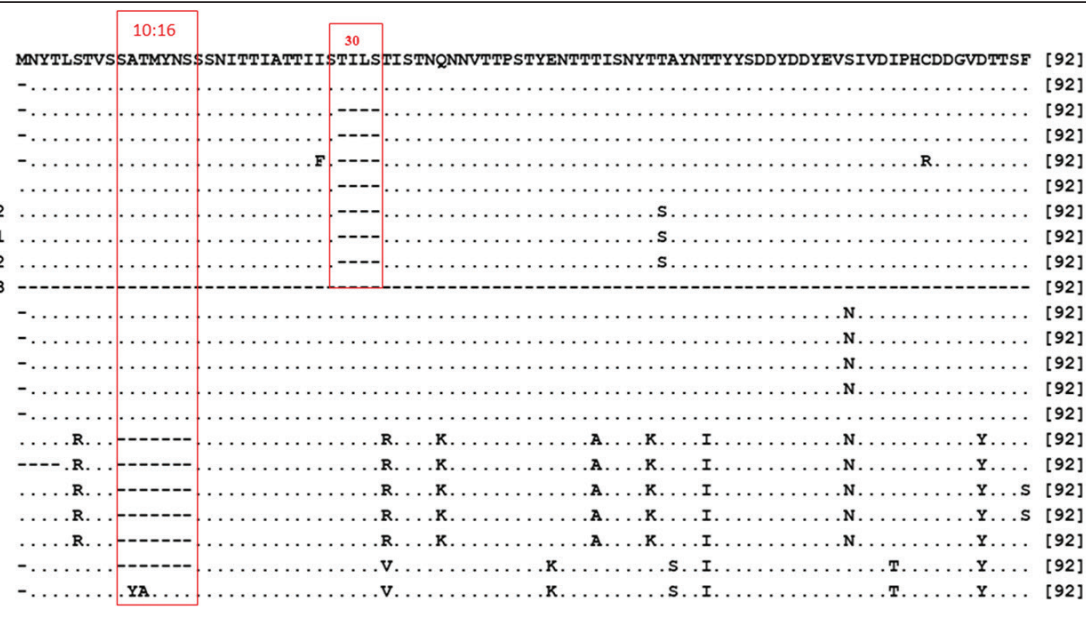

GLITIYSTIFFLGLFGNI IVLTVLRKYKIKTIQDMFLLNLTISDLIFVLVFPFNLYDSIAKQWSIGDCLCKFKAMFYFVGFYNSMSFITIMS [184]

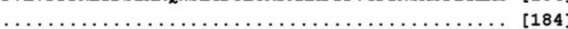

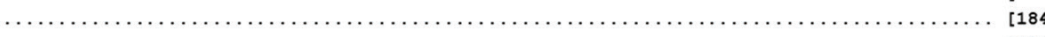

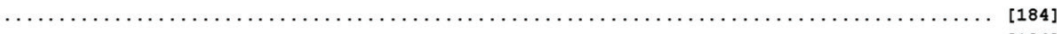

[184]

[184]

$[184]$

$[184]$

(.......

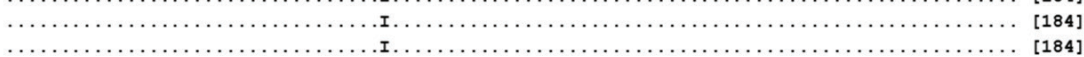

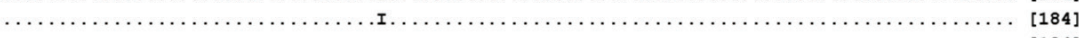

.

(n.

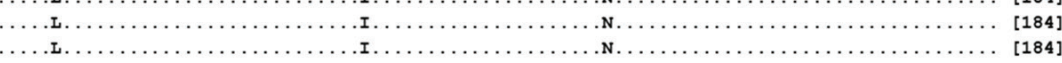

…

IDRYLAVVHPVKSMPIRTKRYGIVLSMVVWIVSTIESEPIMLFYETKKVYGITYCHVFYNDNAKIWKLFINFEINIFGMIIPLTILIYCYYK [276] ........................ [276]

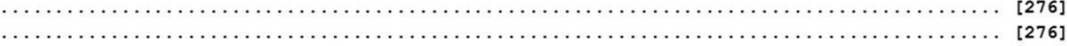

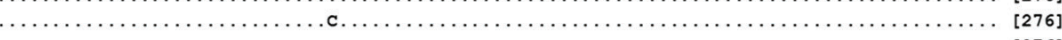

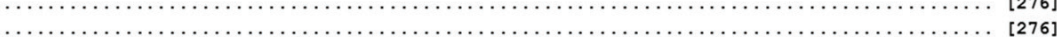

$[276]$

(276]

$[276]$

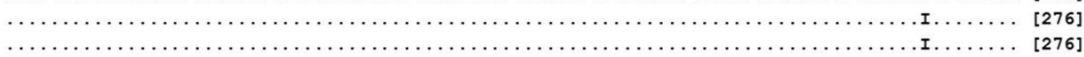



[276]

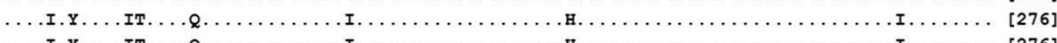

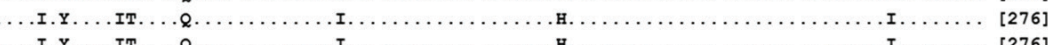

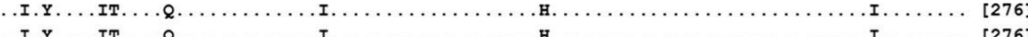

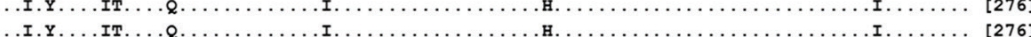

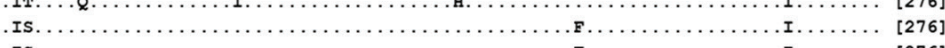

ILNTLKTSQTKNKKAIKMVELIVICSVLFLLPFSVTVEVSSIYLINVESGCMALREVNLAVHVAEIVSLCHCFINPLIYAFCSREFTKK [365]

$[365]$

[365]



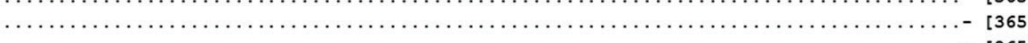

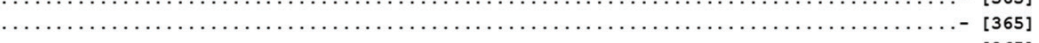

…

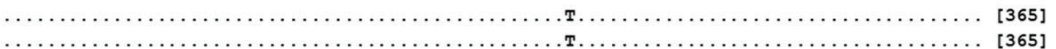

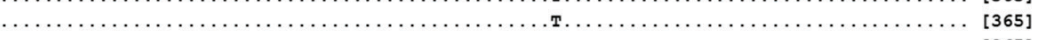

(n.

(n.m.

…

(n.

Dots indicate identical amino acids, Red box denote the site of amino acids deletion $(10: 16)(30: 33)$, and red-colored letters denote sequences obtained in the current study 
Table-2: Differences in amino acid motifs between Capripoxviruses field and vaccine strains in $\mathrm{G}$ protein-coupled receptors gene.

\begin{tabular}{lcccccccccccccccccc}
\hline Amino acid position & $\mathbf{6}$ & $\mathbf{1 0}$ & $\mathbf{1 1}$ & $\mathbf{1 2}$ & $\mathbf{1 3}$ & $\mathbf{1 4}$ & $\mathbf{1 5}$ & $\mathbf{1 6}$ & $\mathbf{3 0}$ & $\mathbf{3 1}$ & $\mathbf{3 2}$ & $\mathbf{3 3}$ & $\mathbf{3 4}$ & $\mathbf{3 9}$ & $\mathbf{4 9}$ & $\mathbf{5 3}$ & $\mathbf{5 8}$ & $\mathbf{6 0}$ \\
\hline LSDV field (MH427384) & $\mathrm{S}$ & $\mathrm{S}$ & $\mathrm{A}$ & $\mathrm{T}$ & $\mathrm{M}$ & $\mathrm{Y}$ & $\mathrm{N}$ & $\mathrm{S}$ & - & - & - & - & $\mathrm{T}$ & $\mathrm{Q}$ & $\mathrm{E}$ & $\mathrm{T}$ & $\mathrm{T}$ & $\mathrm{A}$ \\
LSDV vaccine (KX764645) &. &. &. &. &. &. &. &. & $\mathrm{T}$ & $\mathrm{I}$ & $\mathrm{L}$ & $\mathrm{S}$ &. &. &. &. &. &. \\
SPPV field (MH427389) & $\mathrm{R}$ & - & - & - & - & - & - & - & $\mathrm{T}$ & $\mathrm{I}$ & $\mathrm{L}$ & $\mathrm{S}$ & $\mathrm{R}$ & $\mathrm{K}$ &. & $\mathrm{A}$ & $\mathrm{K}$ &. \\
SPPV vaccine (KF495237) & $\mathrm{R}$ & - & - & - & - & - & - & - & $\mathrm{T}$ & $\mathrm{I}$ & $\mathrm{L}$ & $\mathrm{S}$ & $\mathrm{R}$ & $\mathrm{K}$ &. & $\mathrm{A}$ & $\mathrm{K}$ &. \\
Amino acid position & 63 & 76 & 80 & 88 & 99 & 117 & 127 & 149 & 191 & 193 & 198 & 199 & 204 & 218 & 238 & 249 & 268 & 328 \\
LSDV field (MH427384: 88) & $\mathrm{T}$ & $\mathrm{S}$ & $\mathrm{I}$ & $\mathrm{D}$ & $\mathrm{S}$ & $\mathrm{R}$ & $\mathrm{M}$ & $\mathrm{D}$ & $\mathrm{V}$ & $\mathrm{H}$ & $\mathrm{M}$ & $\mathrm{P}$ & $\mathrm{R}$ & $\mathrm{T}$ & $\mathrm{Y}$ & $\mathrm{I}$ & $\mathrm{T}$ & $\mathrm{M}$ \\
LSDV vaccine (KX764645) &. & $\mathrm{N}$ &. &. &. &. & $\mathrm{I}$ &. &. &. &. &. &. &. &. &. & $\mathrm{I}$ & $\mathrm{T}$ \\
SPPV field (MH427389) & $\mathrm{I}$ & $\mathrm{N}$ &. & $\mathrm{Y}$ & $\mathrm{L}$ &. & $\mathrm{I}$ & $\mathrm{N}$ & $\mathrm{I}$ & $\mathrm{Y}$ & $\mathrm{I}$ & $\mathrm{T}$ & $\mathrm{Q}$ & $\mathrm{I}$ & $\mathrm{H}$ &. & $\mathrm{I}$ & $\mathrm{T}$ \\
SPPV vaccine (KF495237) & $\mathrm{I}$ & $\mathrm{N}$ &. & $\mathrm{Y}$ & $\mathrm{L}$ &. & $\mathrm{I}$ & $\mathrm{N}$ & $\mathrm{I}$ & $\mathrm{Y}$ & $\mathrm{I}$ & $\mathrm{T}$ & $\mathrm{Q}$ & $\mathrm{I}$ & $\mathrm{H}$ &. & $\mathrm{I}$ & $\mathrm{T}$ \\
\hline
\end{tabular}

Dashes and dots indicate missing amino acids and conserved residues at the corresponding positions, respectively. Blue boxes denote the eight unique profiles for LSDV, SPPV, and GTPV amino acids. Red boxes denote amino acid differences between LSDV and SPPV field strains. Green boxes denote amino acid differences between LSDV field and vaccine strains. LSDV=Lumpy skin disease virus, SPPV=Sheep pox virus, GTPV=Goat poxvirus

\section{DNA extraction}

DNA was extracted from skin lesions, infected cell culture, LSDV Neethling vaccine strain, and Romanian SPPV strain using a DNA/RNA Extraction Kit (Intron, Pathogen, Spin, cat\#17154, Korea) according to the manufacturer's instructions.

PCR

The primers were developed to amplify the entire GPCR gene at position 6961-8119 according to Le Goff et al. [16]. The primers have the following gene sequences: 5'-TTAAGTA A A G C ATA A C T C C A A C A A A A AT G - 3 ' and 5'-TTTTTTTATTTTTTATCCAATGCTAATACT-3'). PCR was carried out in a total volume of $50 \mu \mathrm{l}$ containing $25 \mu \mathrm{l}$ master mix (Thermo Scientific, DreamTaq PCR Master Mix 2× Cat\# K1071, USA), $1 \mu \mathrm{l}$ of each primer (20 pmol), $5 \mu \mathrm{l}$ of extracted DNA, and $18 \mu \mathrm{l}$ of nuclease-free water. Neethling vaccine was used as control positive while Nuclease-Free water was used as control negative. The thermal profile of PCR was started with an initial denaturation at $94^{\circ} \mathrm{C}$ for $5 \mathrm{~min}$ and 35 cycles of denaturation at $94^{\circ} \mathrm{C}$ for $1 \mathrm{~min}$, annealing at $50^{\circ} \mathrm{C}$ for $1 \mathrm{~min}$, and extension at $72^{\circ} \mathrm{C}$ for $1 \mathrm{~min}$, with a final extension of $7 \mathrm{~min}$. The PCR products were visualized in transilluminator after being electrophoresed in $1.5 \%$ agarose gel.

\section{Sequences and phylogenetic analysis}

PCR amplicons were purified using QIAquick PCR Purification Kit and dispatched to Macrogen ${ }^{\mathrm{TM}}$, Seoul, Korea, for DNA sequencing using two additional primers(5'-GATGAGTATTGATAGATACCTAGCTGTAGTT-3 ' and 5'-TGAGACAATCCAAACCACCAT-3') according to Le Goff et al. [16]. BLAST analysis (http://Zwww. ncbi.nlm.nih.gov/blast) was initially implemented to establish sequence identity to GenBank accessions. Phylogenetic tree and sequence alignments were generated using MEGA(Molecular Evolutionary Genetics Analysis)Version X software. The tree was generated by the neighbor-joining method based on 1000 bootstrapped data sets [17].

\section{Results}

\section{Clinical examination}

Fever, skin lesions scattered in different parts of the body (Figure-1), and enlargement of superficial lymph nodes were observed in examined cattle with or without edema in legs. Edema in brisket was also seen. Within a sheep flock, animals showed signs of cutaneous papules, especially in areas of skin without wool with nasocular discharge and fever.

\section{Virus isolation}

Virus isolation revealed CPE at the third passage on primary ovine fetal kidney and heart cells, characterized by retraction of the cell membrane from surrounding cells, rounding of cells, and margination of the nuclear chromatin (Figure-2).

\section{PCR, gene sequencing, and sequence analyses}

Using primer sequences targeting the entire GPCR gene, a fragment of 1158 bp has been amplified from all DNA extracts (Figure-3). Sequencing analyses of the GPCR gene revealed that five LSDV sequences obtained in the current study (MH427384.1, MH427385.1, MH427386.1, MH427387.1, and MH427388.1) are closely related to each other with nucleotide and amino acid (AA) identity ranged from $99 \%$ to $100 \%$ in between and $98: 99 \%$ with LSDV Neethling vaccine. Comparative sequence analyses of GPCR gene reveal that field LSDV isolates differ from LSDV Neethling vaccine only in four AAs substitution (S/N76, M/I127, T/I268, and M/T328, respectively) and an AA deletion (Table-1) where AA at positions 30-33 was observed in MH427384.1, MH427385.1, MH427386.1, and MH427387.1 but not in LSDV Neethling vaccine.

Regarding Romanian SPPV vaccine strain, it was found that AA residues situated in position 10-16 (SATMYNS) in LSDV field isolates are missed in SPPV vaccine; moreover, there are 27 variances in AA motifs between LSDV field isolates and SPPV vaccines were observed along GPCR gene (Tables-1 and 2). On the other hand, no differences between SPPV vaccinal and virulent strains were observed (100\% nucleotide and AA identities). 
To represent the evolutionary relationships among field and vaccinal strains of LSDV and SPPV sequenced in this study and available CaPVs in the database, a GPCRbased phylogenetic tree was generated using the neighbor-joining method on nucleic acid sequences. The tree showed three tight genetic clusters (LSDV, goat poxvirus [GTPV], and SPPV lineages, respectively) (Figure-4). LSDV falls into two subgroups. Our LSDV field isolates were found in subgroup one with other virulent LSDV available in the database. The other subgroup comprised LSDV vaccinal strain including LSDV Neethling vaccine that was sequenced in the current study while Romanian SPPV vaccine strain was clustered in a separate clade with other virulent and vaccine strains of SPPV.

\section{Discussion}

LSD and sheep pox diseases are now considered as endemic diseases in Egypt. Despite the extensive vaccination program adopted by Egyptian veterinary services, LSD and sheep pox are still prevalent and spread throughout the whole country, thereby the present study provides a molecular characterization of LSDV and SPPV recovered from field cases in Egypt and a comparison of Capripoxviruses field and vaccinal strains based on sequence analysis of GPCR gene.

A total of five LSDV and one SPPV were isolated from naturally infected animals with typical clinical features of LSD and sheep pox, respectively, after being confirmed by PCR.

The complete open reading frames of the GPCR gene of isolated viruses were sequenced along with vaccine strains. Comparative sequence analysis revealed that all of the five LSDV isolates are closely related to each other with a nucleotide and AA identity ranged from $99 \%$ to $100 \%$ in between confirming the circulation of the same virus strain.

Egyptian LSDV field isolates were found more related to LSDV Neethling vaccine where it differs only in four AA substitutions and an AA deletion at positions 30-33.

The comparative sequence analysis revealed that the 5-end of GPCR gene of SPPV vaccine was characterized by deletion of 21 nucleotides (7-aa) when it compared with LSDV field isolates. This sheep pox gap was recorded in all isolates and vaccine strains located in the database and was considered as a specific signature for SPPV as reported previously by Le Goff et al. [16]. Many variances in AA motifs between LSDV field isolates and SPPV vaccines were observed along GPCR gene. These variances include the eight unique AAs (S/R6, S/-10, A/-11, T/-12, T/R34, S/ L99, P/T199, and $\mathrm{M} / \mathrm{I} 328$, respectively) (Table-2) that are lineage-specific where AA signatures present either in LSDV or SPPV or GTPV as reported previously by Le Goff et al. [16] and El-Tholoth and El-Kenawy [18]. Interestingly, no differences between SPPV vaccinal and virulent strains were observed.

Phylogenetically, CaPV was delineated into three clades LSDV, GTPV, and SPPV as previously reported by Rouby et al. [19], Rouby [20], Rouby and Aboulsoud [21], and Mafirakureva et al. [22]. LSDV falls into two subgroups. LSDVs isolated in the current study were located in subgroup one with other virulent LSDV available in the database that proves the minimal genetic variation between different LSDV isolates from different locations and indicate the high stability of LSDVs as previously reported by Kara et al. [23]. The other subgroup comprised LSDV vaccinal strains including LSDV Neethling vaccine that was sequenced in the current study. Egyptian LSDV field isolates are more related to LSDV Neethling vaccine strain than to Romanian SPPV vaccine strain (currently authorized vaccine against LSD in Egypt). The high genetic relatedness between field LSDV isolates and LSDV Neethling vaccine strain was previously reported [23] and recent researches recommended the use of homologous vaccines for controlling $\mathrm{CaPV}$-induced diseases combined with sufficient vaccination coverage and appropriate control measures [24].

\section{Conclusion}

Comparative sequencing and phylogenetic analyses of GPCR gene revealed a minimal genetic variation between different LSDV isolates from different locations and a close relationship between LSDV Neethling vaccine strain and Egyptian field LSDV isolates. GPCR gene possesses specific signatures for LSDV and SPPV at both nucleotide and AA sequences level and cluster them separately according to their host origin.

\section{Authors' Contributions}

ME designed the study. SRR and AB performed PCR, sequence analysis, and wrote the initial draft of the manuscript. MW and ME revised the manuscript. All authors read and approved the final manuscript.

\section{Acknowledgments}

This work was funded by Middle East for Vaccines (ME VAC®). We want to thank Mohamed Aboel-Khair (University of Sadat city, Egypt) for revising the manuscript.

\section{Competing Interests}

The authors declare that they have no competing interests.

\section{Publisher's Note}

Veterinary World remains neutral with regard to jurisdictional claims in published institutional affiliation.

\section{References}

1. Tuppurainen, E.S.M., Venter, E.H., Shisler, J.L., Gari, G., Mekonnen, G.A., Juleff, N., Lyons, N.A., De Clercq, K., Upton, C., Bowden, T.R., Babiuk, S. and Babiuk, L. A. (2017) Review: Capripoxvirus diseases: Current status and opportunities for control. Transbound. Emerg. Dis., 64(3): 729-745.

2. OIE, World Organization for Animal Health. (2016) Lumpy Skin Disease. OIE Terrestrial Animal Health Code. p1-4. 
Available from: http://www.oie.int/fileadmin/Home/eng/ Health_standards/tahc/current/chapitre_lsd.pdf. Last accessed on 27-10-2019.

3. Coetzer, J.A.W. (2004) Lumpy skin disease. In: Coetzer, J.A.W. and Tustin, R.C., editors. Infectious Diseases of Live-stock. $2^{\text {nd }}$ ed. Cape Town: Oxford University Press. p1268-1276.

4. Babiuk, S., Bowden, T.R., Boyle, D.B., Wallace, D.B. and Kitching, R.P. (2008) Capripoxviruses: An emerging worldwide threat to sheep, goats and cattle. Transbound. Emerg. Dis., 55(7): 263-272.

5. Tuppurainen, E.S. and Oura, C.A. (2012) Review: Lumpy skin disease: An emerging threat to Europe, the Middle East and Asia. Transbound. Emerg. Dis., 59(1): 40-48.

6. Tuppurainen, E. and Oura, C. (2014) Lumpy skin disease: An African cattle disease getting closer to the EU. Vet. Rec., 175(12): 300-301.

7. House, J.A., Wilson, T.M., el Nakashly, S., Karim, I.A., Ismail, I., el Danaf, N., Moussa, A.M. and Ayoub, N.N. (1990) The isolation of lumpy skin disease virus and bovine herpesvirus-4 from cattle in Egypt. J. Vet. Diagn. Invest., 2(2): 111-115.

8. El-Kholy, A.A., Soliman, H.M.T. and Abdelrahman, K.A. (2008) Polymerase chain reaction for rapid diagnosis of a recent lumpy skin disease virus incursion to Egypt. Arab $J$. Biotechnol., 11(2): 293-302.

9. Hota, A., Biswal, S., Sahoo, N., Venkatesan, G., Arya, S., Kumar, A., Ramakrishnan, M.A., Pandey, A.B. and Rout, M. (2018) Seroprevalence of capripoxvirus infection in sheep and goats among different agro-climatic zones of Odisha, India. Vet. World, 11(1): 66-70.

10. Madhavan, A., Venkatesan, G. and Kumar, A. (2016) Capripoxviruses of small ruminants: Current updates and future perspectives. Asian J. Anim. Vet. Adv., 11(12): 757-770.

11. Mangana, O., Kottaridi C. and Nomikou, K. (2008) The epidemiology of sheep pox in Greece from 1987 to 2007. Rev. Sci. Tech., 27(3): 899-905.

12. Kitching, R.P. (2003) Vaccines for lumpy skin disease, sheep pox and goat pox. Dev. Biol. (Basel), 114: 161-167.

13. Tuppurainen, E.S., Pearson, C.R., BachanekBankowska, K., Knowles, N.J., Amareen, S., Frost, L., Henstock, M.R., Lamien, C.E., Diallo, A. and Mertens, P.P. (2014) Characterization of sheep pox virus vaccine for cattle against lumpy skin disease virus. Antiviral Res., 109(100): 1-6.

14. Fatma, M.A., Hend, M.E. and Gamilat, F. (2018) Sporadic cases of lumpy skin disease among cattle in Sharkia province, Egypt: Genetic characterization of lumpy skin disease virus isolates and pathological findings. Vet. World, 11(8): $1150-1158$.

15. Tuppurainen, E.S., Venter, E.H. and Coetzer, J.A. (2005) The detection of lumpy skin disease virus in samples of experimentally infected cattle using different diagnostic techniques. Onderstepoort J. Vet. Res., 72(2): 153-164.

16. Le Goff, C., Lamien, C.E., Fakhfakh, E., Chadeyras, A., Aba-Adulugba, E., Libeau, G., Tuppurainen, E., Wallace, D.B., Adam, T., Silber, R., Gulyaz, V., Madani, H., Caufour, P., Hammami, S., Diallo A. and Albina, E. (2009) Capripoxvirus G-protein-coupled chemokine receptor: A host-range gene suitable for virus animal origin discrimination. J. Gen. Virol., 90(8): 1967-1977.

17. Saitou, N. and Nei, M. (1987) The neighbor-joining method: A new method for reconstructing phylogenetic trees. Mol. Biol. Evol., 4(4): 406-425.

18. El-Tholoth, M. and El-Kenawy, A. (2016) 'G-proteincoupled chemokine receptor gene in lumpy skin disease virus isolates from cattle and water buffalo (Bubalus bubalis) in Egypt. Transbound. Emerg. Dis., 63(6): e288-e295.

19. Rouby, S.R., Hussein, K.H., Aboelhadid, S.M. and El Sherif, A.M. (2017) Role of Rhipicephalus annulatus tick in transmission of lumpy skin disease virus in naturally infected cattle in Egypt. Adv. Anim. Vet. Sci., 5(4): 185-191.

20. Rouby, S.R. (2018) RPO30 gene based PCR for detection and differentiation of lumpy skin disease virus and sheep poxvirus field and vaccinal strains. Vet. Sci., 4(1): 1-8.

21. Rouby, S. and Aboulsoud E. (2016) Evidence of intrauterine transmission of lumpy skin disease virus. Vet. J., 209: 193-195.

22. Mafirakureva, P., Saidi, B. and Mbanga, J. (2017) Incidence and molecular characterisation of lumpy skin disease virus in Zimbabwe using the P32 gene. Trop. Anim. Health Prod., 49(1): 47-54

23. Kara, P.D., Afonso, C.L., Wallace, D.B., Kutish, G.F., Abolnik, C., Lu, Z., Vreede, F.T., Taljaard, L.C., Zsak, A., Viljoen G.J. and Rock, D.L. (2003) Comparative sequence analysis of the South African vaccine strain and two virulent field isolates of lumpy skin disease virus. Arch. Virol., 148(7): 1335-1356.

24. Tuppurainen, E. and Galon, N. (2016) Technical Item II Lumpy Skin Disease: Current Situation in Europe and Neighbouring Regions and Necessary Control Measures to Halt the Spread in South-East Europe. Technical Report. OIE Regional Commission, Europe.

\section{$* * * * * * * *$}

